\title{
Analisis Pengaruh Inovasi Produk Terhadap Keunggulan Bersaing Pada UKM "Duren Kamu Pasti Kembali" di Kota Serang
}

\author{
Imas Fatimah Hasnatika ${ }^{1 *}$ dan Ida Nurnida² \\ ${ }^{1}$ Fakultas Komunikasi Bisnis, Universitas Telkom, Indonesia \\ ${ }^{2}$ Fakultas Komunikasi Bisnis, Universitas Telkom, Indonesia
}

\begin{abstract}
:
The study was conducted to determine the effect of product innovation on competitive advantage at SME of "Duren Kamu Pasti Kembali" in Serang City. This study uses quantitativeand was analyzed descriptively the hypothesis were tested by using simple linear regression analysis. This study uses descriptive research-causality. Sampling technicque used was saturated sampling type under non-probability sampling, with the 19 respondents. Based on the results of testing the hypothesis with the t-test, product innovation significantly influenced on competitive advantage at SME "Duren KPK" in Serang City. The results of coefficient of determination showed that product innovation at SME "Duren KPK" was able to explain 77,8\% competitive advantage, and the remaining 22,2\% was influenced by other factors not examined in this research. The conclusion of this study is product innovation at SME "Duren KPK" is categorized as good, but there are several aspects that need to be improved such as product innovation that is still easily imitated by other competitors, and the price of products that are not yet affordable.
\end{abstract}

Keywords: product innovation, competitive advantage, SME

PENDAHULUAN

\section{Latar Belakang}

Buah durian merupakan salah satu jenis buah yang sangat disukai di Asia Tenggara, terutama di Indonesia. Nama durian sendiri terinspirasi dari kulitnya yang keras dan berlekuk-lekuk tajam menyerupai duri. Buah durian dikenal dengan sebutan king of fruit karena memiliki aroma serta rasa yang sangat khas dan melekat.

Berdasarkan observasi peneliti, minat masyarakat untuk mengkonsumsi durian

*Email korespondensi:

Imas Fatimah Hasnatika

imasfatimahhasnatika@student.telkomuniversity. ac.id semakin tinggi. Saat ini tidak hanya orang tua saja yang sangat menikmati durian, tetapi anak kecil dan remaja sangat menikmati buah durian. Hal ini memacu para petani untuk berlomba membudidayakan tanaman durian. Saat ini tidak hanya di Pulau Sumatera dan Pulau Kalimantan saja yang dapat menghasilkan buah durian, tetapi di Pulau Jawa pun sudah banyak yang membudidayakan tanaman durian sehingga banyak menciptakan peluang menjadi pengusaha durian di berbagai daerah, salah satunya Kota Serang - Banten.

Berdasarkan fenomena yang terjadi, hal tersebut sangat memicu pebisnis dalam 
membangun sebuah UKM (Usaha Kecil dan Menengah) yang terkait dengan buah durian. Menurut laporan Global Entrepreneurship Indeks dalam teks: (Zuraya, 2018), Indonesia menduduki peringkat ke-94, berada dibawah Negara-negara Asia lainnya. Berdasarkan jumlah wirausaha di Indonesia pada saat ini, masih menunjukkan persentase yang sangat kecil dibandingkan Negara maju yang memiliki rata - rata $14 \%$, yaitu $3,1 \%$ dari total penduduk 226 jiwa.

Menurut teks: (Admin Pena Merdeka, 2017), Kepala Dinas Pertanian Provinsi Banten, menyatakan bahwa Pemerintah terus melakukan tata ruang pembangunan pertanian di Banten termasuk Kota Serang, seperti penempatan sentra budidaya durian dan kemudian akan dilakukan pemetaan wilayah hingga kebun serta bibit durian. Menurut data yang ada pada Dinas Perindustrian, Perdagangan, Koperasi, dan UMKM serta UKM Kota Serang, peningkatan jumlah UMKM dan UKM tahun 2017-2018 cukup pesat dan signifikan. Saat ini usaha buah durian di Kota Serang sudah tidak asing lagi, seperti ditampilkan pada Tabel 1.

Berdasarkan data-data pada tabel diatas, persaingan bisnis buah durian pada Kota Serang yang semakin ketat, mempengaruhi pengusaha durian untuk melakukan berbagai cara dalam mempertahankan konsumen yang dimilikinya.

Selanjutnya, berdasarkan observasi peneliti, dari beberapa usaha durian diatas, salah satu usaha durian yang sangat diminati adalah usaha pada UKM "Duren KPK". Usaha "Duren Kamu Pasti Kembali" (Duren KPK) termasuk ke dalam golongan UKM, karena di antaranya memiliki asset $>$ Rp. 250 juta dan omset sekitar Rp. 600 juta per bulan.

Inovasi produk yang dilakukan oleh UKM "Duren KPK" antara lain: mengubah buah durian menjadi pancake durian ukuran medium, pancake durian ukuran mini, ice cream durian, roti durian, ketan durian lumer, dan jus durian. Disamping inovasi tersebut, UKM "Duren KPK" juga menciptakan inovasi pengepakkan buah durian secara praktis, seperti durian kupas, durian kupas montong, daging durian, dan frozen durian in cup. Inovasi - inovasi yang dilakukan UKM "Duren KPK" sejalan dengan pendapat Suryani, yang menyatakan bahwa "Salah satu upaya yang harus dilakukan oleh pengusaha adalah dengan melakukan sebuah inovasi terhadap produknya" (Suryani, 2008: 5).

\section{Tabel 1 Daftar Perkembangan UKM Durian} di Kota Serang

\begin{tabular}{|c|c|c|c|c|c|c|c|}
\hline \multirow[t]{2}{*}{ No } & \multirow{2}{*}{$\begin{array}{c}\text { Nama } \\
\text { UKM } \\
\text { Durian }\end{array}$} & \multicolumn{3}{|c|}{$\begin{array}{c}\text { Omset perbulan } \\
\text { (Rp.) }\end{array}$} & \multicolumn{3}{|c|}{ Asset (Rp.) } \\
\hline & & 2016 & 2017 & 2018 & 2016 & 2017 & 2018 \\
\hline 1 & $\begin{array}{l}\text { Duren } \\
\text { KPK }\end{array}$ & $50 \mathrm{jt}$ & $\begin{array}{c}300 \\
\text { jt }\end{array}$ & $\begin{array}{c}600 \\
\text { jt }\end{array}$ & $50 \mathrm{jt}$ & $\begin{array}{c}100 \\
\text { jt }\end{array}$ & $\begin{array}{c}250 \\
\text { jt }\end{array}$ \\
\hline 2 & $\begin{array}{l}\text { Gudang } \\
\text { Duren }\end{array}$ & - & - & - & - & - & - \\
\hline 3 & $\begin{array}{l}\text { Durian } \\
\text { Medan } \\
\text { CSM }\end{array}$ & $10 \mathrm{jt}$ & $45 \mathrm{jt}$ & $65 \mathrm{jt}$ & - & - & $\begin{array}{c}100 \\
\text { jt }\end{array}$ \\
\hline 4 & $\begin{array}{l}\text { Kedai Sop } \\
\text { Duren }\end{array}$ & $30 \mathrm{jt}$ & $\begin{array}{c}100 \\
\text { jt }\end{array}$ & $\begin{array}{c}150 \\
\mathrm{jt}\end{array}$ & - & $\begin{array}{c}100 \\
\mathrm{jt}\end{array}$ & $\begin{array}{c}200 \\
\text { jt }\end{array}$ \\
\hline 5 & $\begin{array}{l}\text { Durian Pak } \\
\text { Uban }\end{array}$ & - & - & - & - & - & - \\
\hline 6 & $\begin{array}{l}\text { Duren } \\
\text { Jatohan } \\
\text { Haji Arif }\end{array}$ & - & - & - & - & - & $\begin{array}{c}200 \\
\text { jt }\end{array}$ \\
\hline 7 & $\begin{array}{l}\text { Café } \\
\text { Duren } \\
\text { Woke }\end{array}$ & & $30 \mathrm{jt}$ & $80 \mathrm{jt}$ & & - & - \\
\hline 8 & $\begin{array}{l}\text { PT. } \\
\text { Kinarya } \\
\text { Satria } \\
\text { Durian }\end{array}$ & & $\begin{array}{c}100 \\
\text { jt }\end{array}$ & $\begin{array}{c}150 \\
\mathrm{jt}\end{array}$ & & - & - \\
\hline 9 & Kedai Biru & & $30 \mathrm{jt}$ & $50 \mathrm{jt}$ & & - & - \\
\hline 10 & $\begin{array}{l}\text { Radja Sop } \\
\text { Duren }\end{array}$ & & - & - & & - & - \\
\hline 11 & $\begin{array}{l}\text { Durian } \\
\text { Mama'Hits }\end{array}$ & & $35 \mathrm{jt}$ & $50 \mathrm{jt}$ & & - & $50 \mathrm{jt}$ \\
\hline 12 & $\begin{array}{l}\text { Sop } \\
\text { Durian } \\
\text { Alfin }\end{array}$ & & & $50 \mathrm{jt}$ & & & $35 \mathrm{jt}$ \\
\hline 13 & $\begin{array}{l}\text { Durian } \\
\text { Kupas } \\
\text { Kang TB }\end{array}$ & & & $\begin{array}{c}100 \\
\mathrm{jt}\end{array}$ & & & $30 \mathrm{jt}$ \\
\hline 14 & $\begin{array}{l}\text { Aneka } \\
\text { Durian } \\
\text { Medan }\end{array}$ & & & - & & & - \\
\hline 15 & $\begin{array}{l}\text { Sahara } \\
\text { Durian } \\
\text { Farm }\end{array}$ & & & - & & & - \\
\hline
\end{tabular}

Sumber : Diolah Oleh Peneliti, 2018

Berbagai inovasi yang dilakukan UKM "Duren KPK" adalah dalam upaya 
mendapatkan keunggulan bersaing, sehingga usaha UKM "Duren KPK" dapat bertahan dan berkelanjutan dalam kondisi bisnis yang semakin ketat. Pada sisi lain, keunggulan bersaing suatu perusahaan akan menghasilkan kepuasan pada konsumen, karena dengan keunggulan yang dimilikinya merupakan suatu cerminan bahwa produk yang ditawarkan telah memenuhi keinginan dan kebutuhan konsumen, selain itu perusahaan juga memiliki nilai yang positif dimata konsumen. Hal tersebut sejalan dengan pendapat Day et al (dalam Sukarmen, 2013: 66).

Sedangkan ahli lainnya, Porter (dalam Setiawan, 2012: 14), menjelaskan bahwa keunggulan bersaing merupakan jantung dari kinerja pemasaran dan strategi pemasaran dalam melakukan persaingan.

UKM "Duren KPK" sangat berkomitmen dan terus melakukan inovasi, baik dalam produk maupun proses dengan tujuan untuk mempertahankan keunggulan diantara pesaing lainnya. Dengan kata lain, keunggulan bersaing yang dimiliki oleh UKM "Duren KPK" didukung dengan adanya inovasi - inovasi yang selalu dilakukan perusahaan secara terus - menerus. Berdasarkan latar belakang tersebut, maka peneliti tertarik untuk melakukan penelitian tentang "Analisis Pengaruh Inovasi Produk terhadap Keunggulan Bersaing pada UKM "Duren Kamu Pasti Kembali" di Kota Serang".

\section{Identifikasi Masalah}

Berdasarkan latar belakang di atas, dapat dirumuskan permasalahan penelitian sebagai berikut :

1. Bagaimana inovasi produk pada UKM "Duren KPK" di Kota Serang?

2. Bagaimana keunggulan bersaing pada UKM "Duren KPK" di Kota Serang?
3. Bagaimana pengaruh inovasi produk terhadap keunggulan bersaing pada UKM "Duren KPK" di Kota Serang?

\section{Tujuan Penelitian}

Berdasarkan identifikasi masalah, maka dapat diketahui bahwa tujuan dari diadakannya penelitian ini adalah :

1. Untuk mengetahui dan menganalisis inovasi produk pada UKM "Duren KPK" di Kota Serang.

2. Untuk mengetahui dan menganalisis keunggulan bersaing pada UKM "Duren KPK" di Kota Serang.

3. Untuk mengetahui dan menganalisis pengaruh inovasi produk terhadap keunggulan bersaing pada UKM "Duren KPK" di Kota Serang.

\section{TINJAUAN PUSTAKA \\ Inovasi Produk}

Menurut Myers \& Marquis (dalam Kotler, 2016: 454), inovasi produk merupakan hasil dari berbagai macam proses yang digabungkan dan saling mempengaruhi antara satu dengan yang lain. Dengan dilakukannya inovasi produk, diharapkan dapat meningkatkan keputusan pembelian konsumen.

Hal tersebut didukung oleh Kotabe (dalam Tamamudin, 2012: 289), yang menunjukkan bahwa meningkatnya kinerja perusahaan melalui peningkatan keputusan pembelian, dipengaruhi oleh inovasi produk yang dilakukan perusahaan.

Menurut Kotler \& Keller (2016: 454), dimensi dari inovasi produk diantaranya:

1. Produk baru bagi dunia;

2. Perbaikan produk yang sudah ada;

3. Lini produk baru;

4. Tambahan pada lini produk yang telah ada. 


\section{Keunggulan Bersaing}

Keunggulan bersaing sangat penting bagi perusahaan. Menurut Satyagraha (dalam Sukarmen et al, 2013: 66), keunggulan bersaing adalah kemampuan dalam memberikan nilai lebih terhadap produknya yang dapat menciptakan manfaat bagi konsumen dibandingkan dengan pesaing lainnya.

Menurut ahli lainnya, Sunyoto (2015:1), keunggulan bersaing dapat dicapai dengan mengembangkan produk secara spesial dan lebih menguntungkan dibandingkan dengan para pesaing. Menurut Sunyoto (2015: 3), terdapat lima dimensi yang dapat digunakan untuk menentukan keunggulan bersaing. Kelima dimensi tersebut adalah :

1. Harga;

2. Kualitas;

3. Pengiriman yang dapat diandalkan;

4. Inovasi produk; dan

5. Time to market.

\section{Inovasi Produk dan Keunggulan Bersaing} Dalam beberapa penelitian, disebutkan bahwa inovasi akan berimbas pada keunggulan bersaing suatu perusahaan. Perusahaan yang melakukan inovasi secara rutin akan mampu meningkatkan keunggulan bersaing dengan pesaing.

Menurut para ahli, Sunyoto (2015: 41) berpendapat bahwa kemampuan dalam menciptakan inovasi produk merupakan sumber daya saing yang sangat penting dan strategis dalam membangun keunggulan bersaing. Jadi, terdapat hubungan positif yang signifikan antara inovasi produk dengan keunggulan bersaing.

\section{METODE PENELITIAN}

Penelitian ini menggunakan pendekatan kuantitatif dengan jenis penelitian deskriptif-kausalitas. Teknik pengumpulan data dilakukan dengan membagikan kuesioner kepada para agen UKM "Duren KPK", dan dengan studi pustaka. Pengambilan sampel dilakukan dengan teknik non-probability sampling denganjenis sampling jenuh, dan dengan jumlah responden sebanyak 19 orang. Teknik analisis data yang digunakan adalah analisis deskriptif dan analisis regresi linear sederhana.

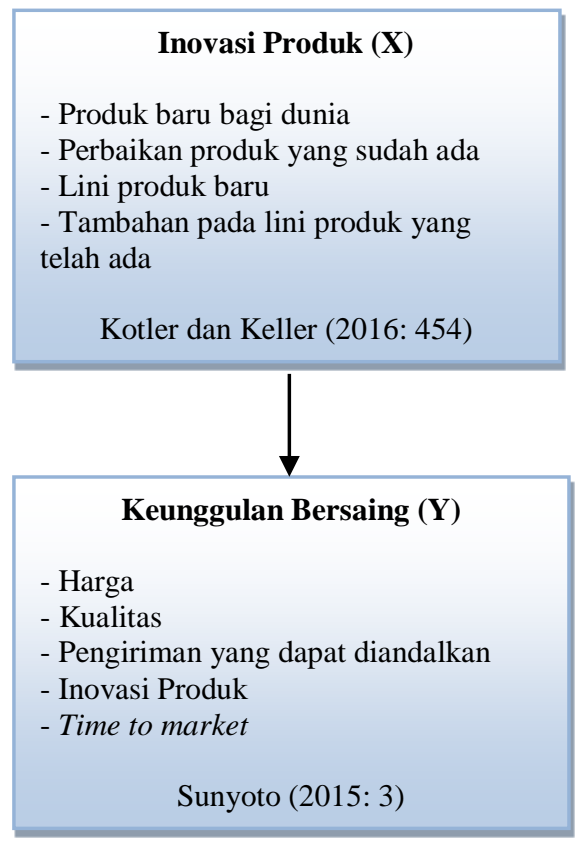

Gambar 1 Model Penelitian

\section{PEMBAHASAN}

\section{Uji Validitas}

Uji validitas dilakukan dengan tingkat kepercayaan 5\% $(\alpha=0,05)$, sehingga diperoleh angka korelasi tabel ( $\mathrm{r}$ tabel) sebesar 0,456 .

Tabel 2 Hasil Uji Validitas Variabel Inovasi Produk (X)

\begin{tabular}{|c|c|c|c|}
\hline Item & r Hitung & r Tabel & Kesimpulan \\
\hline 1 & 0,900 & 0,456 & VALID \\
\hline 2 & 0,716 & 0,456 & VALID \\
\hline 3 & 0,596 & 0,456 & VALID \\
\hline 4 & 0,768 & 0,456 & VALID \\
\hline 5 & 0,769 & 0,456 & VALID \\
\hline 6 & 0,457 & 0,456 & VALID \\
\hline
\end{tabular}

Sumber: Olahan Data SPSS, 2018 
Dikatakan valid jika koefisien korelasi person product moment hitung lebih besar daripada nilai korelasi tabel, artinya $\mathrm{r}$ dikatakan valid jika >0,456. Hasil uji validitas dari penelitian ini ditampilkan pada Tabel 2 dan Tabel 3.

\section{Tabel 3 Hasil Uji Validitas Variabel} Keunggulan Bersaing (Y)

\begin{tabular}{|c|c|c|c|}
\hline Item & r Hitung & r Tabel & Kesimpulan \\
\hline 1 & 0,707 & 0,456 & VALID \\
\hline 2 & 0,739 & 0,456 & VALID \\
\hline 3 & 0,806 & 0,456 & VALID \\
\hline 4 & 0,838 & 0,456 & VALID \\
\hline 5 & 0,699 & 0,456 & VALID \\
\hline 6 & 0,748 & 0,456 & VALID \\
\hline 7 & 0,699 & 0,456 & VALID \\
\hline 8 & 0,799 & 0,456 & VALID \\
\hline 9 & 0,843 & 0,456 & VALID \\
\hline 10 & 0,903 & 0,456 & VALID \\
\hline 11 & 0,859 & 0,456 & VALID \\
\hline 12 & 0,846 & 0,456 & VALID \\
\hline 13 & 0,871 & 0,456 & VALID \\
\hline
\end{tabular}

Sumber: Olahan Data SPSS, 2018

\section{Uji Reliabilitas}

Uji reliabilitas ini menggunakan metode Cronbach Alpha. Hasil uji reliabilitas dari penelitian ini, yaitu :

Tabel 4 Hasil Uji Reliabilitas Variabel Inovasi Produk $(\mathrm{X})$

\begin{tabular}{|c|c|c|}
\hline $\begin{array}{c}\text { Cronbach's } \\
\text { Alpha }\end{array}$ & $\begin{array}{c}\mathrm{N} \text { of } \\
\text { Items }\end{array}$ & Keterangan \\
\hline 0,785 & 6 & $\begin{array}{c}\text { Reliabilitas } \\
\text { Diterima }\end{array}$ \\
\hline
\end{tabular}

Sumber: Olah Data SPSS, 2018

Tabel 5 Hasil Uji Reliabilitas Variabel Keunggulan Bersaing (Y)

\begin{tabular}{|c|c|c|}
\hline $\begin{array}{c}\text { Cronbach's } \\
\text { Alpha }\end{array}$ & N of Items & Keterangan \\
\hline 0,950 & 13 & $\begin{array}{c}\text { Reliabilitas } \\
\text { Baik }\end{array}$ \\
\hline
\end{tabular}

Sumber: Olahan Data SPSS, 2018

\section{Analisis Deskriptif}

Berdasarkan hasil tanggapan responden mengenai pengaruh inovasi produk, didapat skor total 519 dengan persentase $91,05 \%$. Jumlah skor tersebut dimasukkan ke dalam garis kontinum yang pengukurannya ditentukan dengan cara :

Skor Interpretasi $=[($ skor total $)$ : nilai maksimum] x $100 \%$

$$
\begin{aligned}
& =[519: 570] \times 100 \% \\
& =91,05 \%
\end{aligned}
$$

Hasil analisis deskriptif mengenai pengaruh inovasi produk termasuk kedalam kategori sangat tinggi dengan persentase 91,05\%. Berdasarkan hasil tanggapan responden mengenai keunggulan bersaing, didapat skor total 1,107 dengan persentase $89,63 \%$. Jumlah skor tersebut dimasukkan ke dalam garis kontinum yang pengukurannya ditentukan dengan cara :

Skor Interpretasi $=[$ (skor total $)$ : nilai maksimum] x $100 \%$

$$
\begin{aligned}
& =[1.107: 1.235] \times 100 \% \\
& =89,63 \%
\end{aligned}
$$

Hasil analisis deskriptif mengenai pengaruh inovasi produk termasuk kedalam kategori sangat tinggi dengan persentase $89,63 \%$.

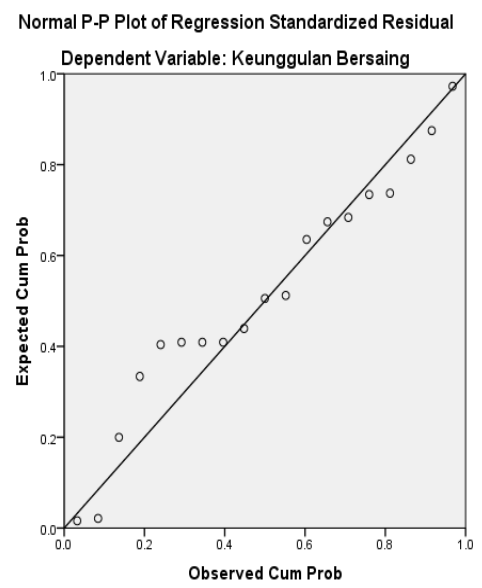

Gambar 2 Grafik Normal Probability Plot Sumber : Olahan Data SPSS, 2018

\section{Uji Normalitas}

Uji normalitas dilakukan untuk mengetahui apakah data yang diperoleh berdistribusi normal atau tidak normal. 
Gambar 2 menjelaskan bahwa data pada variabel yang digunakan dinyatakan berdistribusi normal. Hal ini dapat dilihat dengan adanya titik-titik data yang menyebar di sekitar garis diagonal. Untuk lebih memastikan data tersebut berdistribusi normal atau tidaknya, perlu dilakukan uji One-Sample Kolmogrov-Smirnov Test.

Tabel 6 One-Sample KolmogorovSmirnov Test

\begin{tabular}{|ll|r|}
\hline & & $\begin{array}{c}\text { Unstandardized } \\
\text { Residual }\end{array}$ \\
\hline $\mathrm{N}$ & & 19 \\
Normal & Mean & .0000000 \\
Parameters & Stb & Std. \\
& Deviation & 2.10025548 \\
Most Extreme & Absolute & .191 \\
Differences & Positive & .099 \\
& Negative & -.191 \\
Test Statistic & & .191 \\
Asymp. Sig. (2-tailed) & $.068^{\mathrm{c}}$ \\
\hline
\end{tabular}

Sumber : Olahan Data SPSS, 2018

Pada tabel di atas, dapat diketahui bahwa keseluruhan data berdistribusi normal karena memiliki nilai sig 0,068 diatas nilai alpha 0,05 .

\section{Uji Heteroskedastisitas}

Uji heteroskedastisitas bertujuan untuk menguji apakah dalam model regresi terjadi ketidaksamaan variance dari residual. Salah satu cara menguji adanya heteroskedastisitas melalui metode scatterplot, dengan mengamati pola titiktitiknya. Jika titik-titik pada scatterplot menyebar dan tidak membentuk pola tertentu, maka dapat dikatakan bahwa tidak terjadi heterokesdastisitas.

Hasil pengolahan data untuk melihat ada tidaknya heterokesdastisitas ditampilkan pada Gambar 3. Berdasarkan Gambar 3, terlihat titik-titik menyebar secara acak, hal ini dapat disimpulkan bahwa tidak terjadi heteroskedastisitas, sehingga model regresi layak untuk digunakan dalam melakukan pengujian.

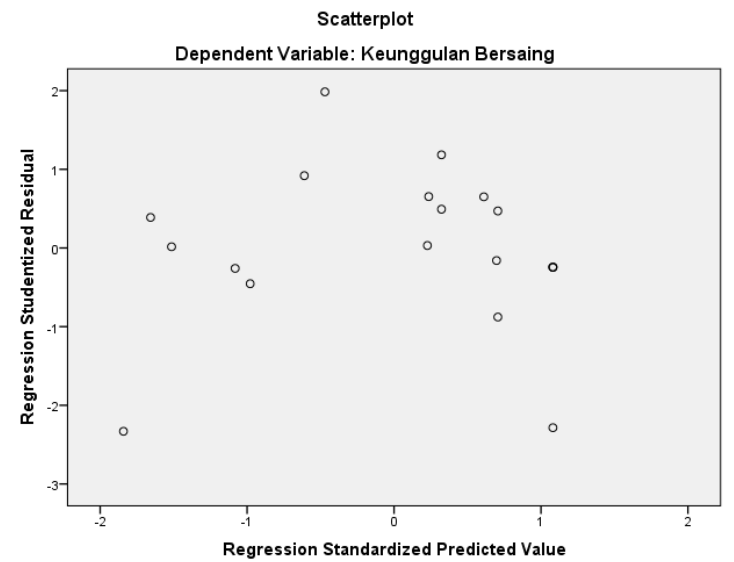

Gambar 3 Grafik Scatterplot

Sumber: Olahan Data SPSS, 2018

\section{Uji Homogenitas}

Berikut ini merupakan tabel hasil dari uji homogenitas :

Tabel 7 Hasil Uji Homogenitas

\begin{tabular}{|c|c|c|c|}
\hline $\begin{array}{c}\text { Levene } \\
\text { Statistic }\end{array}$ & df1 & df2 & Sig. \\
\hline 2.219 & 4 & 11 & .134 \\
\hline
\end{tabular}

Sumber: Olahan Data SPSS, 2018

Dari hasil olahan data melalui spss, dapat dilihat bahwa nilai signifikansi $>0,05$ $(0,134>0,05)$. Jadi, dapat disimpulkan bahwa variabel inovasi produk dan keunggulan bersaing adalah sama, maka hal ini telah memenuhi asumsi dasar homogenitas.

Tabel 8 Hasil Uji Regresi Linear Sederhana

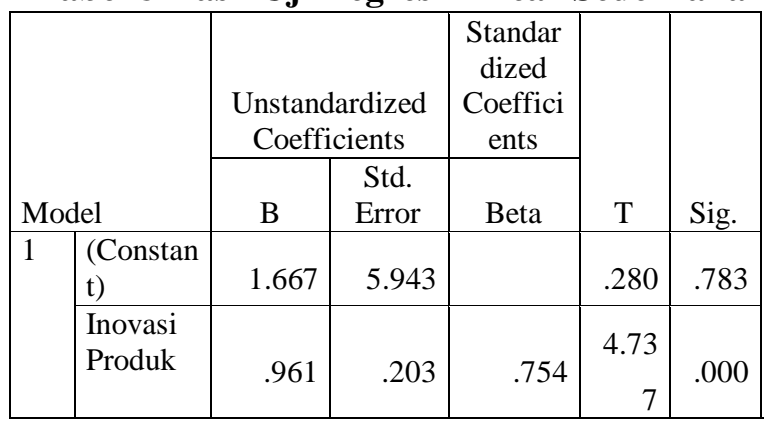

Sumber: Olahan Data SPSS, 2018

\section{Analisis Regresi Linear Sederhana}

Analisis ini dilakukan untuk mengetahui arah hubungan antara variabel 
inovasi produk dengan variabel keunggulan bersaing apakah positif atau negatif. Tabel hasil uji regresi linear sederhana ditampilkan pada Tabel 8. Perhitungan regresi linear sederhana dihitung sebagai berikut :

$$
\begin{gathered}
\mathrm{Y}=\mathrm{a}+\mathrm{bX} \\
\mathrm{Y}=1,667+0,961 \mathrm{X}
\end{gathered}
$$

Berdasarkan persamaan tersebut, dapat diuraikan bahwa:

Konstanta $(\mathrm{a})=1,667$. Ini menunjukkan nilai konstan, yaitu pengaruh inovasi produk terhadap keunggulan bersaing pada UKM "Duren KPK" di Kota Serang sebesar 1,667. Koefisien (b) $=0,961$. Ini menunjukkan bahwa variabel inovasi produk berpengaruh secara positif terhadap keunggulan bersaing pada UKM "Duren KPK" di Kota Serang.

\section{Pengujian Hipotesis (Uji t)}

Berikut ini merupakan tabel hasil dari uji $t$ :

\begin{tabular}{|c|c|c|c|c|c|c|}
\hline \multirow{3}{*}{\multicolumn{2}{|c|}{ Mo }} & \multirow{2}{*}{\multicolumn{2}{|c|}{$\begin{array}{c}\text { Unstandardiz } \\
\text { ed } \\
\text { Coefficients }\end{array}$}} & \multirow{3}{*}{$\begin{array}{c}\text { Standar } \\
\text { dized } \\
\text { Coeffic } \\
\text { ients } \\
\text { Beta } \\
\end{array}$} & \multirow{3}{*}{$\mathrm{t}$} & \multirow{3}{*}{ Sig. } \\
\hline & & & & & & \\
\hline & & B & $\begin{array}{c}\text { Std. } \\
\text { Error }\end{array}$ & & & \\
\hline \multirow[t]{2}{*}{1} & \begin{tabular}{|l|} 
(Const \\
ant)
\end{tabular} & 2.600 & 6.476 & & .402 & .694 \\
\hline & \begin{tabular}{|l|} 
Inovasi \\
Produk
\end{tabular} & .930 & .220 & .737 & 4.226 & .001 \\
\hline
\end{tabular}

\section{Tabel 9 Hasil Uji Hipotesis (Uji t}

Sumber : Olahan Data SPSS, 2018

Berdasarkan tabel hasil uji t diatas, dapat diuraikan bahwa :

1. Variabel inovasi produk (x) memiliki nilai t hitung lebih besar dari t tabel. Karena nilai t hitung sebesar 4,226 dan t tabel dari 17 responden (n-2) sebesar 1,739. Maka dapat disimpulkan bahwa hasil dari uji t yaitu 4,226 > 1,739 dan artinya variabel inovasi produk (x) memiliki pengaruh terhadap variabel keunggulan bersaing (y).

2. Variabel inovasi produk (x) memiliki nilai signifikan lebih kecil dari $\alpha$ (alpha), yaitu $0,001<0,05$. Maka dapat disimpulkan bahwa adanya signifikansi antara variabel inovasi produk (x) terhadap variabel keunggulan bersaing (y).

\section{Koefisien Determinasi}

Koefisien determinasi $\left(\mathrm{r}^{2}\right)$ digunakan untuk mengetahui seberapa besar persentase pengaruh variabel independen secara bersama-sama terhadap variabel dependen. Berikut ini merupakan tabel hasil dari koefisien determinasi :

Tabel 10 Hasil Uji Koefisien Determinasi

\begin{tabular}{|l|c|r|r|r|}
\hline Model & R & $\begin{array}{c}\text { R } \\
\text { Square }\end{array}$ & $\begin{array}{c}\text { Adjusted } \\
\text { R Square }\end{array}$ & $\begin{array}{c}\text { Std. Error of } \\
\text { the Estimate }\end{array}$ \\
\hline 1 & $.882^{\mathrm{a}}$ & .778 & .765 & 2.161 \\
\hline
\end{tabular}

Sumber : Olahan Data SPSS, 2018

Rumus koefisien determinasi adalah $\mathrm{Kd}=\mathrm{r}^{2} \mathrm{x} 100 \%$. Berdasarkan hasil tabel di atas diketahui nilai $\mathrm{r}^{2}$ adalah 0,677. Maka perhitungan koefisien determinasi adalah sebagai berikut:

$$
\begin{aligned}
\mathrm{KD} & =0,778 \times 100 \% \\
& =77,8 \%
\end{aligned}
$$

Dapat diartikan bahwa besarnya pengaruh variabel inovasi produk (x) terhadap variabel keunggulan bersaing (y) sebesar $77,8 \%$, sedangkan sisanya sebesar $22,2 \%$ dipengaruhi oleh variabel lain yang tidak diteliti dalam penelitian ini.

\section{KESIMPULAN DAN SARAN \\ Kesimpulan}

Berdasarkan hasil penelitian dan pembahasan mengenai pengaruh inovasi produk melalui keunggulan bersaing pada UKM "Duren KPK" di Kota Serang, dapat diambil beberapa kesimpulan sebagai berikut:

1. Inovasi produk pada UKM "Duren KPK" di Kota Serang. 
Berdasarkan hasil analisis deskriptif, inovasi produk di mata responden secara keseluruhan berada dalam kategori sangat baik. Hal ini menunjukkan bahwa UKM "Duren KPK" telah melaksanakan keempat dimensi dari inovasi produk yang meliputi produk baru bagi dunia, perbaikan produk yang sudah ada, lini produk baru, dan tambahan pada lini produk yang telah ada, dan sudah mendapat tanggapan yang baik dimata responden. Dari keseluruhan item, pernyataan inovasi produk yang mendapat tanggapan responden paling rendah walaupun masih dalam kategori baik, yaitu pada dimensi lini produk baru, mengenai inovasi produk durian yang dilakukan oleh UKM "Duren KPK" sulit ditiru oleh pesaing lainnya.

2. Keunggulan bersaing pada UKM "Duren KPK" di Kota Serang.

Berdasarkan hasil analisis deskriptif, keunggulan bersaing di mata responden secara keseluruhan berada dalam kategori sangat baik. Hal ini menunjukkan bahwa UKM "Duren KPK" telah melaksanakan kelima dimensi dari keunggulan bersaing yang meliputi harga, kualitas, pengiriman yang dapat diandalkan, inovasi produk, dan time to market. Dari keseluruhan item pernyataan keunggulan bersaing yang mendapat tanggapan responden paling rendah walaupun masih dalam kategori sangat baik, yaitu pada dimensi harga, mengenai harga produk durian yang ditawarkan oleh UKM "Duren KPK" terjangkau.

3. Pengaruh inovasi produk terhadap keunggulan bersaing pada UKM "Duren KPK" di Kota Serang.

Berdasarkan uji hipotesis, hasil uji $\mathrm{t}$ variabel inovasi produk (x) memiliki pengaruh signifikan secara parsial terhadap variabel keunggulan bersaing (y) dengan nilai t hitung $>\mathrm{t}$ tabel sebesar 4,226>1,739 dan dengan nilai signifikan $0,001<0,05$. Hasil uji koefisien determinasi $\left(\mathrm{r}^{2}\right)$ yang bertujuan untuk mengetahui seberapa besar pengaruh inovasi produk terhadap keunggulan bersaing memiliki persentase sebesar $77,8 \%$.

\section{Saran}

Penelitian ini tentunya masih mengandung banyak kekurangan dalam pelaksanaannya. Oleh sebab itu, peneliti akan memberikan saran-saran untuk UKM "Duren KPK" dan juga untuk peneliti selanjutnya.

1. Saran Bagi Perusahaan:

Berdasarkan hasil kesimpulan yang telah diuraikan di atas, peneliti dapat memberikan beberapa saran yang kiranya dapat bermanfaat bagi pihak UKM "Duren KPK", diantaranya yaitu :

a. Hal-hal positif yang perlu dipertahankan oleh UKM "Duren KPK" :

1) Berdasarkan hasil analisis deskriptif pada variabel inovasi produk, hal yang harus dipertahankan dan ditingkatkan yaitu pada dimensi tambahan lini produk yang telah ada, mengenai inovasi produk harus dilakukan secara terus-menerus untuk membuat konsumen tidak merasa bosan.

2) Hal positif yang harus dipertahankan dan ditingkatkan dari variabel keunggulan bersaing, yaitu mengenai kualitas produk yang memuaskan.

b. Hal-hal negatif yang masih perlu diperbaiki oleh UKM "Duren KPK" :

1) Saran mempertahankan dan meningkatkan strategi inovasi produk yang sudah dinyatakan sangat baik menurut tanggapan responden. Pernyataan yang mendapat persentase terendah menurut 
responden yaitu pada dimensi lini produk baru, mengenai inovasi produk durian yang dilakukan oleh UKM "Duren KPK" sulit ditiru oleh pesaing lainnya. Disarankan agar UKM "Duren KPK" dapat menciptakan produk inovasi buah durian yang lebih kreatif dan menarik sehingga sulit untuk ditiru oleh pesaing lainnya.

2) Berdasarkan hasil analisis deskriptif pada variabel keunggulan bersaing, persentase yang paling rendah yaitu pada dimensi harga, mengenai harga produk durian yang ditawarkan oleh UKM "Duren KPK" terjangkau. Disarankan agar UKM "Duren KPK" dapat menciptakan produk durian dengan packaging lebih kecil dan dengan harga lebih rendah dari biasanya, sehingga produk durian yang ditawarkan oleh UKM "Duren KPK" lebih terjangkau.

2. Saran Bagi Peneliti Selanjutnya:

Penelitian ini hanyameneliti tentang pengaruh inovasi produk terhadap keunggulan bersaing pada UKM "Duren KPK" di Kota Serang, maka untuk peneliti selanjutnya disarankan untuk :

a. Melakukan penelitian pada UKM durian lainnya dengan tujuan mendapatkan hasil yang dapat dijadikan sebagai bahan perbandingan.

b. Melakukan penelitian dengan menambahkan variabel lain yang belum diteliti, seperti variabel orientasi pasar, kreativitas produk, dan keberagaman produk, yang kemungkinan memiliki pengaruh besar terhadap keunggulan bersaing.

\section{DAFTAR PUSTAKA}

Admin. (2017, Mei 22). "Dinas Pertanian Banten Tunjuk Kabupaten Serang
Sentra Budidaya Durian” (Diakses 2

Oktober 2018

dari:www.penamerdeka.com/14782).

Kotler, P., \& Armstrong, G. (2016). Principle of Marketing $\left(16^{\text {th }}\right.$ ed). North Carolina: Pearson Education Limited. Setiawan, H. (2012). Pengaruh Orientasi Pasar, Orientasi Teknologi, dan Inovasi Produk terhadap Keunggulan Bersaing Usaha Songket Skala Kecil di Kota Palembang. Jurnal Orasi Bisnis, 8 (2).

Sunyoto, D. (2015). Keunggulan Bersaing. Jakarta: PT. Buku Seru.

Sukarmen, P. (2013). Analisis Pengaruh Inovasi Produk terhadap Kepuasan Konsumen dengan Keunggulan Bersaing sebagai Variabel Intervening pada Produk Gula Pasir Sebelas (GUPALAS) Pabrik Gula Semboro PTP Nusantara (Persero). Tesis. Universitas Jember.

Suryani, T. (2008). Perilaku Konsumen: Implikasi pada Strategi Pemasaran. Yogyakarta: Graha Ilmu.

Tamamudin. (2012). Analisis Pengaruh Pengenalan Merek, Persepsi Kualitas, Harapan Konsumen, dan Inovasi Produk terhadap Keputusan Membeli dan Dampaknya pada Loyalitas Konsumen (Studi Kasus: Produk Batik Sutra Halus merek Tamima). Jurnal Penelitian, 9 (2), 283-300.

Zuraya, N. (2018, Oktober 18). "Tingkat Kewirausahaan di Indonesia Rendah" (Diakses 14 Desember 2018 dari:www.republika.co.id/berita/eko nomi/korporasi/18/10/18/pgsax3383. 